\title{
EDITORIAL
}

\section{DESDE LA EVIDENCIA EN SALUD PÚBLICA A LA ACCIÓN. LA IMPORTANCIA DEL TRABAJO EN EQUIPO PARA EL ÉXITO DEL PLAN NACIONAL DE PREVENCIÓN Y CONTROL DEL TABAQUISMO}

\author{
José $\mathbf{M}^{\mathrm{a}}$ Martín Moreno
}

Dirección General de Salud Pública. Ministerio de Sanidad y Consumo.

El consumo masivo de tabaco en nuestra sociedad se ha convertido en uno de los problemas de Salud Pública más preocupantes. España sigue siendo uno de los países de la Unión Europea con mayor consumo y, aunque la prevalencia está descendiendo globalmente de manera paulatina, todavía persiste una alarmante tendencia en ciertos grupos poblacionales, particularmente entre las mujeres más jóvenes.

Para entender la situación del tabaquismo en España hemos de reconocer la coexistencia de múltiples factores de carácter económico y social, tales como la producción, un alto nivel de tolerancia y permisividad hacia su consumo y hacia las prácticas comerciales más agresivas, o una elevada accesibilidad al producto a causa de la política de precios y puntos de venta.

Hemos de reconocer que en España la vertebración social en torno al abordaje del tabaquismo como problema de Salud Pública ha sido históricamente débil. Se partía de una limitada sensibilización de la sociedad

Correspondencia:

Dr. Jose María Martín Moreno

Director General de Salud Pública

Ministerio de Sanidad y Consumo

Paseo del Prado 18-20

28071-Madrid

Correo electrónico: DGSP@msc.es en la percepción del riesgo para la salud que presenta la exposición al tabaco, fruto del generalizado consumo (alta prevalencia) alcanzado en décadas anteriores. Por otro lado, la contribución y movilización de los profesionales sanitarios ante el problema del tabaquismo, que ha sido el motor fundamental para la acción decidida en los países anglosajones, no se ha producido en nuestro país hasta fechas más recientes. Eso sí, dicha contribución ha irrumpido con fuerza y ahora tiene gran valor.

Asi las cosas, en la percepción de los especialistas conocedores de esta problemática de Salud Publica quedaba subyacente una cierta frustración. Mientras la evidencia del enorme impacto negativo del Tabaco sobre la salud se acumulaba de manera inexorable, y aunque en las dos últimas décadas se habían ido incorporando medidas muy importantes desde todos los ámbitos (incluyendo desde la Administración Central del Estado, las Comunidades Autónomas y las Corporaciones Locales), existía un cierto desajuste entre la magnitud de un problema señalado por todos como prioritario y la limitación de las medidas y recursos articulados como repuesta.

Específicamente, durante el periodo liderado por la Ministra Ana Pastor, se han pro- 
ducido importantes hechos que de forma muy sintética revisaremos a continuación.

En primer lugar, y enmarcada en las acciones europeas e internacionales en este campo, tuvimos la ocasión de transponer una Directiva Europea en forma de Real Decreto por el que se regulan los contenidos máximos de nicotina, alquitrán y monóxido de carbono de los cigarrillos, el etiquetado de los productos del tabaco, así como las medidas relativas a ingredientes y denominaciones de los mismos, Real Decreto que fue aprobado en Consejo de Ministros el 18 de octubre de 2002 (RD 1079/2002, publicado en el BOE de 19 de octubre 2002). Teniendo como fecha horizonte el 30 de septiembre de 2003, las empresas tabaqueras habrán de ajustarse a las disposiciones que establece este Real Decreto.

Por otro lado, los ministros de Sanidad de la Unión Europea aprobaron el pasado 2 de diciembre de 2002 la futura normativa por la que se prohibirá la publicidad del tabaco y su promoción mediante actividades de patrocinio de acontecimientos. El 20 de junio de 2003, tras superar los trámites preceptivos, dicha norma fue publicada en el Diario Oficial de la Unión Europea. La Directiva contempla la supresión de la publicidad y patrocinio de los productos de tabaco en radio, sociedad de la información, la publicidad en prensa y publicaciones impresas y el patrocinio de acontecimientos o actividades en los que participen varios Estados miembros, se celebren en varios Estados miembros o tengan de cualquier otro modo de efecto transfronterizo. Pese a que la fecha tope de transposición a nuestro ordenamiento jurídico del texto de la Directiva es la del 31 de julio de 2005, en España se está trabajando ya en la transposición de esta Directiva.

Otro punto de referencia esencial es el Convenio Marco para el Control del Tabaco de la Organización Mundial de la Salud (OMS), aprobado por la Asamblea Mundial de la Salud celebrada en Ginebra (del 19 al
21 de Mayo). Este tratado internacional, en cuya elaboración España ha sido uno de los Estados miembro que ha contribuido de forma activa, supone el mayor esfuerzo hasta ahora realizado en el ámbito de las políticas de Salud Pública por la OMS. El acuerdo ha sido posible a pesar de las resistencias mostradas por algunos países y las fuertes presiones en contra ejercidas por sectores industriales. El Convenio Marco abre importantes esperanzas a una nueva acción global, coordinada y más efectiva en el mundo para garantizar el derecho a la salud, a la libertad de elegir el propio estilo de vida, a la información veraz sobre riesgos y al derecho a respirar aire no contaminado por humo de tabaco. El grupo de Estados Miembro de la Unión Europea ha sido de los primeros en ratificar dicho Convenio Marco, que requiere de una serie de mínimos a incorporar en las políticas de cada país, incluyendo la introducción de medidas amplias de prohibición de publicidad, promoción y patrocinio de marcas de tabaco, la mejora de la información dirigida a las personas que fuman sobre los contenidos tóxicos de cada marca de tabaco, la adopción de políticas económicas disuasorias, la protección frente al aire contaminado por humo de tabaco a toda la población, el desarrollo de programas de prevención, y el ofrecimiento de programas eficaces de tratamiento de la dependencia al tabaco.

En línea con todo lo anteriormente expresado, quizá el avance del que todos nos sentimos más satisfechos en España es el que ha supuesto la elaboración y aprobación del Plan Nacional de Prevención y Control del Tabaquismo 2003-2007 (PNPCT). Este plan fue acordado el 19 de Septiembre de 2002 por la Comisión de Salud Pública del Consejo Interterritorial del Sistema Nacional de Salud, tras lo cual se elevó al Pleno del Consejo. Dicho órgano otorgó al plan su aprobación por unanimidad el 13 de Enero de 2003. A partir de ahí, la iniciativa se puso formalmente en marcha mediante la constitución de sus órganos de dirección según lo estable- 
cido en el Real Decreto 548/2003, de 9 de mayo, por el que se crean las estructuras del PNPCT (BOE de 13 de Mayo de 2003). Una de las virtudes de este plan es su carácter multisectorial. De hecho, su órgano de liderazgo es la Comisión Intersectorial de Dirección que, presidida por la Ministra de Sanidad y Consumo, está compuesta por dos representantes del Pleno del Consejo Interterritorial del Sistema Nacional de Salud; dos representantes de la Comisión de Salud Pública de dicho Consejo; sendos representantes, con rango de Director General, de los Ministerios de Educación, Cultura y Deporte, Trabajo y Asuntos Sociales, Economía, Hacienda e Interior; y el presidente del Comité Nacional para la Prevención del Tabaquismo; junto a la persona que ostenta la secretaría de dicha Comisión del Plan (en este momento la Subdirectora General de Promoción de la Salud y Epidemiología) y el Director General de Salud Pública. Por otra parte, el Comité Ejecutivo del PNPCT incluye a todos los coordinadores autonómicos, además de la secretaría del Plan (que ostenta el Ministerio de Sanidad y Consumo), con todo lo cual se asegura la intersectorialidad e interterritorialidad de esta iniciativa.

Pero no debemos olvidar que poder disponer hoy de este Plan ha sido fruto del trabajo en equipo y del mayor consenso para su elaboración y desarrollo. Así, a partir del encargo de la Ministra de Sanidad y Consumo y del propio Consejo Interterritorial del Sistema Nacional de Salud, el texto del Plan surgió a partir del Grupo de Trabajo de Tabaco, constituido en la Ponencia de Promoción de la Salud de la Comisión de Salud Pública. Aunque el conjunto de la Comisión (constituida por representantes de todas las Comunidades y Ciudades Autónomas y del Ministerio de Sanidad y Consumo) colaboró en la tarea, el Grupo de Trabajo de Tabaco específicamente constituido a este efecto, estaba formado por técnicos de las Comunidades Autónomas de Andalucía, Aragón, Canarias, Extremadura, Galicia, Navarra y Comunidad Valenciana y técnicos de la Sub- dirección General de Promoción de la Salud y Epidemiología del Ministerio de Sanidad y Consumo. De esta forma se elaboraron sucesivos borradores que fueron revisados no sólo por los Directores Generales de Salud Pública y técnicos de las Comunidades y Ciudades Autónomas, sino también por otros departamentos y unidades ministeriales (tales como Ministerio de Interior, Instituto de la Mujer, o Instituto de la Juventud), colegios profesionales (médicos, farmacéuticos, diplomados universitarios de enfermería, odontólogos y estomatólogos...), expertos y profesionales destacados en este campo, organizaciones sindicales y sociales, y el propio Comité Nacional para la Prevención del Tabaquismo (organización que prácticamente representa al conjunto de personas del mundo sanitario involucrado en este campo, dado que incluye en torno a unas 40 sociedades científicas y asociaciones profesionales).

El PNCPT es en realidad un instrumento de apoyo para avanzar en la aplicación de políticas integradas, globales y eficaces para el control del tabaquismo y la contribución de los distintos sectores sociales para su desarrollo consolidará la actuación en la línea más adecuada y permitirá observar los frutos en el futuro inmediato. El respaldo de la población a las medidas propuestas es el mejor garante de la continuidad y el éxito frente a las presiones de sectores minoritarios, y el trabajo sinérgico y en equipo será fundamental para el desarrollo de esta iniciativa.

En definitiva, hoy somos todos conscientes de que el tabaquismo ocupa un lugar destacado dentro los problemas más importantes de Salud Pública. Actualmente existe evidencia científica incuestionable que demuestra que el tabaquismo genera graves daños a la salud, no sólo a la de quienes fuman, sino también a la de aquellos que de forma involuntaria se ven expuestos al humo del tabaco. 
Como dice Julio Frenk (anterior Director Ejecutivo de la OMS y actual Ministro de Salud de México): Hay que decirlo con claridad, el tabaco no es un bien de consumo, es un mal de consumo. La visión integral de este problema, nos exige no sólo reflexionar acerca de lo que significa la epidemia del tabaquismo desde el punto de vista estricto de pérdida de salud, sino además del impacto económico y social que representa, para así continuar trabajando en el desarrollo y puesta en marcha del Plan, con un profundo sentido ético y un compromiso firme en el marco global de las políticas, estrategias y acciones que logren enfrentar con éxito esta verdadera epidemia.
Así, además de seguir trabajando en las acciones programadas en el Plan, avanzando para conseguir despertar el interés individual, familiar y colectivo en el tema, debemos mantener el espíritu crítico que nos ayude a conseguir que las acciones formuladas se conviertan en una realidad y se alcancen los objetivos planteados: disminuir la prevalencia del tabaquismo (previniendo la incorporación de nuevos fumadores), garantizar el derecho a respirar aire libre de la contaminación por el humo del tabaco (potenciando los espacios sin humo) y fomentar la norma social de no fumar. Sabemos que tenemos ante nosotros un reto importante, pero también estamos seguros que, si trabajamos de forma conjunta, lo conseguiremos. 